\title{
Trends in summer presence of fin whales in the Western Mediterranean Sea Region: new insights from a long-term monitoring program
}

\author{
Paola Tepsich ${ }^{\text {Corresp., } 1}$, Ilaria Schettino ${ }^{2}$, Fabrizio Atzori ${ }^{3}$, Marta Azzolin ${ }^{4,5}$, Ilaria Campana ${ }^{6,7}$, Lara Carosso $^{7}$, \\ Simone Cominelli ${ }^{8}$, Roberto Crosti ${ }^{9}$, Léa David ${ }^{10}$, Nathalie Di-Méglio ${ }^{10}$, Francesca Frau ${ }^{3}$, Martina Gregorietti ${ }^{11}$, \\ Veronica Mazzucato $^{7}$, Clara Monaco ${ }^{12,13}{ }^{\text {, Aurelie Moulins }}{ }^{1}$, Miriam Paraboschi ${ }^{7}$, Giuliana Pellegrino ${ }^{7,12}$, \\ Massimiliano Rosso ${ }^{1}$, Marine Roul ${ }^{10}$, Sébastien Saintignan ${ }^{5}$, Antonella Arcangeli ${ }^{9}$ \\ ${ }^{1}$ CIMA Research Foundation, Savona, Italy \\ 2 Department of Biology, University of Padua, Padova, Italy \\ 3 Capo Carbonara Marine Protected Area, Villasimius, Italy \\ 4 Life and System Biology Department, University of Turin, Torino, Italy \\ 5 Gaia Research Institute Onlus, Torino, Italy \\ 6 Department of Ecological and Biological Sciences, Ichthyogenic Experimental Marine Center (CISMAR), Tuscia University, Tarquinia, Italy \\ 7 Accademia del Leviatano, Maccarese, Italy \\ 8 NorthernEDGE Lab, Memorial University of Newfoundland, Newfoundland, Canada \\ 9 ISPRA, Rome, Italy \\ 10 EcoOcéan Institut, Montpellier, Francia \\ 11 Department of Earth and Marine Science, University of Palermo, Palermo, Italy \\ 12 Marecamp Association, Aci Castello, Italy \\ 13 Department of Agriculture, Food and Environment (Di3A), University of Catania, Catania, Italy \\ Corresponding Author: Paola Tepsich \\ Email address: paola.tepsich@cimafoundation.org
}

Background: the Mediterranean subpopulation of fin whale Balaenoptera physalus (Linnaeus, 1758) has recently been listed as Vulnerable by the IUCN Red List of threatened species. The species is also listed as species in need of strict protection under the Habitat Directive and is one of the indicators for the assessment of Good Environmental Status under the MSFD. Reference values on population abundance and trends are needed in order to set the threshold values and to assess the conservation status of the population.

Methods: yearly summer monitoring using ferries as platform of opportunity was performed since 2008 within the framework of the FLT Med Network. Data were collected along several fixed transects crossing the Western Mediterranean basin and the Adriatic and Ionian region. Species presence, expressed by density recorded along the sampled transects, was inspected for assessing interannual variability together with group size. Generalized Additive Models were used to describe density trends over a 11 years' period (2008-2018). A spatial multi-scale approach was used to highlight intra-basin differences in species presence and distribution during the years.

Results: summer presence of fin whales in the western Mediterranean area showed a strong interannual variability, characterized by the alternance of rich and poor years. Small and large groups of fin whales were sighted only during rich years, confirming the favorable feeding condition influencing species presence. Trends highlighted by the GAM can be summarized as positive from 2008 to 2013, and slightly

Peer] reviewing PDF | (2020:02:45467:3:0:NEW 13 Nov 2020) 
negative from 2014 to 2018. The sub-areas analysis showed a similar pattern, but with a more stable trend during the second period in the Pelagos Sanctuary sub-area, and a negative one in the other two sub-areas. Our findings further confirm the need for an integrated approach foreseeing both, large scale surveys and yearly monitoring at different spatial scales to correct and interpret the basin wide abundance estimates, and to correlate spatial and temporal trends with the ecological and anthropogenic drivers. 


\section{Trends in summer presence of fin whales in the Western}

2 Mediterranean Sea Region: new insights from a long-term

3 monitoring program

5 Paola Tepsich ${ }^{1}$, Ilaria Schettino ${ }^{2}$, Fabrizio Atzori ${ }^{3}$, Marta Azzolin ${ }^{4,5}$, Ilaria Campana ${ }^{6,7}$, Lara

6 Carosso $^{7}$, Simone Cominelli ${ }^{8}$, Roberto Crosti ${ }^{9}$, Léa David ${ }^{10}$, Nathalie Di-Méglio ${ }^{10}$, Francesca

7 Frau $^{3}$, Martina Gregorietti ${ }^{11}$, Veronica Mazzucato ${ }^{7}$, Clara Monaco 12,13, Aurélie Moulins ${ }^{1}$,

8 Miriam Paraboschi ${ }^{7}$, Giuliana Pellegrino ${ }^{7,12}$, Massimiliano Rosso ${ }^{1}$, Marine Roul ${ }^{10}$, Sébastien

9 Saintingan 5, Antonella Arcangeli 9.

${ }^{1}$ CIMA Research Foundation, 17100 Savona, SV, Italy

$12{ }^{2}$ Department of Biology, University of Padua, 35131 Padova, PD, Italy

$13{ }^{3}$ Capo Carbonara Marine Protected Area, 09049 Villasimius, CA, Italy

$14{ }^{4}$ Life and System Biology Department, University of Torino, Torino, Italy

$15{ }^{5}$ Gaia Research Institute Onlus, Torino, Italy

$16{ }^{6}$ Department of Ecological and Biological Sciences, Ichthyogenic Experimental Marine Center

17 (CISMAR), Tuscia University, 01016 Tarquinia, VT, Italy

$18{ }^{7}$ Accademia del Leviatano, 00054 Maccarese, RM, Italy

$19{ }^{8}$ Department of Geography, Memorial University of Newfoundland, Newfoundland and

Labrador, NL A1B 3X9, Canada

${ }^{9}$ ISPRA, 00144 Rome, Italy

${ }^{10}$ EcoOcéan Institut, 34090 Montpellier, France

${ }^{11}$ Department of Earth and Marine Science, Laboratory of Ecology, University of Palermo,

2590128 Palermo, PA, Italy

$26 \quad{ }^{12}$ Marecamp Association, 95021 Aci Castello, CT, Italy

$27{ }^{13}$ Department of Agriculture, Food and Environment (Di3A), University of Catania, 95125

28 Catania, CT, Italy 
34 Corresponding Author:

35 Paola Tepsich ${ }^{1}$

36 CIMA Research Foundation, via Magliotto 2, Savona, 17100 Italy

37 Email address: paola.tepsich@cimafoundation.org

\section{Abstract}

Background: the Mediterranean subpopulation of fin whale Balaenoptera physalus (Linnaeus, 1758) has recently been listed as Vulnerable by the IUCN Red List of threatened species. The species is also listed as species in need of strict protection under the Habitat Directive and is one of the indicators for the assessment of Good Environmental Status under the MSFD. Reference values on population abundance and trends are needed in order to set the threshold values and to assess the conservation status of the population.

Methods: yearly summer monitoring using ferries as platform of opportunity was performed since 2008 within the framework of the FLT Med Network. Data were collected along several fixed transects crossing the Western Mediterranean basin and the Adriatic and Ionian region. Species presence, expressed by density recorded along the sampled transects, was inspected for assessing interannual variability together with group size. Generalized Additive Models were used to describe density trends over a 11 years' period (2008-2018). A spatial multi-scale approach was used to highlight intra-basin differences in species presence and distribution during 53 the years.

54 Results: summer presence of fin whales in the western Mediterranean area showed a strong interannual variability, characterized by the alternance of rich and poor years. Small and large groups of fin whales were sighted only during rich years, confirming the favorable feeding condition influencing species presence. Trends highlighted by the GAM can be summarized as positive from 2008 to 2013, and slightly negative from 2014 to 2018. The sub-areas analysis showed a similar pattern, but with a more stable trend during the second period in the Pelagos

60 Sanctuary sub-area, and a negative one in the other two sub-areas. Our findings further confirm

61 the need for an integrated approach foreseeing both, large scale surveys and yearly monitoring at 
62 different spatial scales to correct and interpret the basin wide abundance estimates, and to

63 correlate spatial and temporal trends with the ecological and anthropogenic drivers.

64

65

66

67

68

69

70

71

72

73

74

75

76

77

\section{Introduction}

The fin whale Balaenoptera physalus (Linnaeus, 1758) is the only commonly sighted mysticete species in the Mediterranean Sea (Notarbartolo di Sciara et al., 2003). Genetic analyses based on both mitochondrial and nuclear DNA indicated that fin whales in the Mediterranean Sea are characterized by genetic isolation with limited but current exchange from the North Atlantic conspecific (Bérubé et al., 1998; Palsbøll et al., 2004).

The species is encountered throughout the basin, although its distribution is patchy (Notarbartolo di Sciara et al., 2003). Movements of the species within the Mediterranean basin do not seem to follow a clear migratory pattern, while instead the species seems to use different movement strategy, ranging between a more "traditional" latitudinal displacement to movement between specific sites characterized by patches of prey abundance, following a behavior defined as nomadic opportunistic (Notarbartolo di Sciara et al., 2016). A general migratory pattern, with summer concentration in higher latitudes in the north-western basin (i.e. mostly in the western Ligurian Sea and Gulf of Lion) and autumn-winter dispersal in most of the basin and towards southern latitudes, has been recently described by different studies (Geijer, Notarbartolo di Sciara \& Panigada, 2016; Arcangeli, Campana \& Bologna, 2017).Three main concentration areas have been identified. The first one is the Gulf of Lions and the Ligurian-CorsicanProvençal Basin, where the highest concentration of fin whales of the entire basin was recorded, especially during summer. Cetacean species concentration in the area has been the main triggering factor towards the institution here of the Pelagos Sanctuary (Notarbartolo-di-Sciara et al., 2008). The persistence in this area is linked with high primary production (Druon et al., 2012), this being the only area with recurrent blooms in the entire Mediterranean basin (D’Ortenzio \& Ribera d'Alcalà, 2009; Mayot, 2015) and consequently sustaining a large biomass of primary production (Orsi Relini et al., 1998; Littaye et al., 2004). Two other hotspots, coinciding with rich areas are also known in the basin: one in the central Tyrrhenian Sea during summer (Arcangeli et al., 2014) and one in the Ionian Sea, around the island of Lampedusa, where a winter-spring feeding ground is reported (Canese et al., 2006; Aïssi et al., 2008). 
92 Fluctuation of local hot-spots with high inter-annual variability were related to the variability in 93 the pattern of productivity (Druon et al., 2012; Morgado et al., 2017), to the influence of both 94 environmental and anthropogenic drivers of changes (Azzellino et al., 2017), and could be linked 95 to biological or behavioural factors (e.g. life stage, gender, group structure) that determine small 96 group/individual flexibility in the pattern of distribution (e.g. (Brown et al., 2016; Arcangeli, 97 Campana \& Bologna, 2017)

98 The Mediterranean sub-population is classified as Vulnerable by the IUCN Red List of 99 endangered species and, according to the last assessment, the population is severely fragmented; 100 furthermore the current population trend is decreasing (Panigada \& Notarbartolo Di Sciara, 101 2012). The species in the basin is facing many anthropogenic threats such as marine traffic and 102 ship strikes (Panigada et al., 2006; David, Alleaume \& Guinet, 2011; Coomber et al., 2016; 103 Peltier et al., 2019), marine litter (Fossi et al., 2014; Di-Méglio \& Campana, 2017), chemical 104 pollution (Marsili \& Focardi, 1996), and noise (Sciacca et al., 2016).

105 Regular systematic studies of fin whale density and abundance in the Mediterranean Basin are 106 part of the requirements of the Marine Strategy Framework Directive (MSFD, 008/56/EC) and 107 the Habitat Directive (HD, 92/43/EEC), but long-term basin wide information is still lacking 108 (Panigada et al., 2017). Fin whale is the only species representative of the baleen whale group in 109 the Mediterranean Sea, and consequently among the elements considered by member state for 110 assessment of the MSFD under the Descriptor 1 - Biodiversity. Species abundance is a primary 111 criteria (Criteria D1C2) required by MSFD for all species group for the assessment of Good

112 Environmental Status (GES). The evaluation of trend in abundance is considered a relevant

113 indicator to set threshold values and to express the extent to which good environmental status is

114 being achieved (Palialexis et al., 2019; Art. 4 of the Decision 2017/848/EU).

115 Abundance and density estimates of fin whales for the Liguro-Provencal Basin (Forcada,

116 Notarbartolo Di Sciara \& Fabbri, 1995; Forcada et al., 1996), relevant to the Pelagos Sanctuary

117 (Gannier, 2006) and for the Ligurian sea (Laran et al., 2010) from ship based surveys performed 118 during summer, showed a strong decreasing trend, even if difficulties in comparing those 119 estimates must be taken into account (Panigada et al., 2011). Latest available abundance and 120 density estimates for this area were obtained by aerial surveys performed in 2009 and from 2010 121 to 2013 from Italian research groups (Panigada et al., 2011, 2017) and from 2011 and 2012 from 122 French groups (Laran et al., 2017). Despite the similar platforms used for the surveys, strong 
123 differences were found in the final estimates: for the Pelagos Sanctuary, as an example, 330

124 (95\%CI 172 - 633) individuals were estimated from the first groups (Panigada et al., 2017) and

125 around 1100 (95\% CI: 600-2400) from the second (Laran et al., 2017).

126 It has to be stressed that no abundance or density estimates exist for all the other areas of the

127 Mediterranean sea. While Panigada et al. (2017) extended survey coverage to the southern areas

128 of the western basin, no fin whale sighting was registered in those areas. Only recently the

129 ACCOMBAMS surveys initiative (Panigada et al., 2019) aimed to fill this knowledge gap, with

130 a survey that covers the entire Mediterranean Basin.

131 The use of ferries as platforms for conducting dedicated research has been increasing in recent

132 years. It has been demonstrated that data collection following specific protocols can result in the

133 successful use of the data for species distribution studies (Kiszka et al., 2007; Arcangeli, Marini

134 \& Crosti, 2012; Aïssi et al., 2015; Correia et al., 2015; Morgado et al., 2017; Azzolin et al.,

135 2020).

136 In the Mediterranean Basin, several research institutions, scientific associations and ferry

137 companies are collaborating in the development of the Fixed Line Transect Mediterranean

138 Monitoring Network (FLT Med Net). This project, coordinated by ISPRA, started in 2007 and it

139 expands year by year, with the adding of new institutions and new monitored routes distributed

140 in the central-western Mediterranean and the Adriatic and Ionian Region. A dedicated protocol is

141 shared by all research groups, ensuring a consistent and coordinated collection of data on

142 cetaceans, sea turtles, seabirds and human impacts, such as marine traffic and marine litter

143 (ISPRA, 2016). Data collected were used for investigating species distribution, habitat

144 preference as well as quantifying impact of human activities.

145 In this work we used data on fin whale distribution collected by the network operating in the

146 central-western Mediterranean and Adriatic region. The dataset encompassed 11 years, allowing

147 an evaluation of short-term trends (Palialexis et al., 2019). We investigated interannual

148 variability in species density, presence and group size in different sub-areas. Finally, we tested

149 the usability of the data to assess a trend, for the purposes of assessment and reporting under the

150 Habitat Directive and MSFD.

\section{Materials \& Methods}

152 Data collection 
153 For this analysis, we used data collected during summer months (considered from late May to 154 end of September), from 2008 to 2018. Analysis was restricted to summer months as only 3 of

155 the monitored routes are covered also during winter time (as ferries either do not travel along 156 those routes during winter or they travel during night time), consequently the winter dataset is 157 not considered representative for the purpose of this analysis. Data were collected from dedicated 158 observers embarked on board ferries along fixed routes, covering the western Mediterranean and 159 Adriatic region. Sampled routes are shown in Figure 1.

160 Surveys were conducted from the ferries' command deck by a team of at least three MMOs 161 (Marine Mammals Observers) that scanned a sea area of approximately $130^{\circ}$ from the bow 162 abeam, to the left and right side of the command deck by naked eye and using binoculars $(7 \times 50)$ 163 to confirm species and group size. The back of the route is scanned only occasionally to avoid 164 risk of re-counting of sightings. Considering the small but still present cross over search area 165 from observers across the bow, sightings that could be duplicate of already registered ones where 166 noted and not considered in the analysis. The same precautionary approach was taken for 167 possible resightings of whales first sighted at long distance and then closer to the ferry, after dive 168 time (set at 10-12 minutes taking into account both diving time of species and ferry speed).

169 Track line of effort was recorded continuously along the survey using a dedicated Global

170 Positioning System (GPS). Weather conditions were recorded at the beginning of the survey and 171 every time a change occurred. Weather data included wind speed and direction, sea state 172 (following the Beaufort scale), cloud cover, visibility and rain. Effort was considered only under 173 optimal conditions (Beaufort equal or less than 4, good visibility). Every time a cetacean sighting 174 occurred, the following data were recorded: time, longitude, latitude, radial distance, angle 175 between sighted animal/group and ferry route, species, number of individuals (expressed as 176 minimum, maximum and best estimation), behavior toward the ferry (indifferent, escaping or 177 approaching) and any peculiar observed behavior.

178 Radial distance was measured using either a rangefinder stick (Wright \& Cosentino, 2015) or a 179 binocular with reticle rangefinder. In this latter case, distances were subsequently converted into 180 kilometric distances applying the formula from Kinzey \& Gerrodette (2003) (see Cominelli et 181 al., 2016 for more details on conversion). Angle between cetacean sighting and ferry course was 182 measured using a compass or a protractor, set with the $0^{\circ}$ coinciding with the bow of the ferry. 183 


\section{Data preparation}

185 All data was imported into the software QGIS and mapped using the EPSG3035 projection. GPS

186 points of the ferry track were used to create a transect for each trip, considering a single trip from

187 port to port. After eliminating points where weather conditions were not ideal and during which

188 observers were not on-effort, total length of each obtained transect was then computed. Transects

189 were then grouped into Transect-Groups according to the route and the sea area covered.

190 Consequently, routes along which sampled transects differ from outbound and return, thus not

191 sampling the exact same transect, were divided into separate transect groups (Table 1-Figure 2).

192 For each transect group then, the maximum length recorded for a single transect was used in

193 order to set a threshold value for assessing transect representativeness: within each transect

194 group, transects not reaching the $30 \%$ of the maximum length were discarded from the analysis.

195 For each transect finally, total number of fin whale sightings and total number of individuals

196 sighted was computed.

197

198 For the study we set two different geographic scales. The overall dataset was used to describe

199 distribution and trend of the species at global scale, encompassing the western Mediterranean

200 area and the Adriatic region. We then highlighted 4 sub-areas: the Pelagos Sanctuary (PEL),

201 which includes the transect groups TI, TB, NC, NB, SC, SB, N_LB, S_LB, LGA, E_CVBA; the

202 Western Pelagos (WP), including the transect groups TAL and W_CVBA; the South-Eastern

203 Pelagos (SEP), defined by the transect groups CTCV, PATU, N_TUCV, S_TUCV, CAPA and

204 the Adriatic region (AD), with the transect groups N_AP and S_AP ( Figure 2).

205

206 A strip-transect framework analysis was applied to the dataset. To this end, each transect was

207 transformed into a strip-transect. In order to take into account possible differences in species

208 detectability, distance sampling analysis has been applied. Width of each transect was then set

209 based on the computation of the Effective Strip Width (ESW), ensuring the assumption of a

$210100 \%$ probability of sightings within the strip. Several factors were considered to rule out

211 possible elements influencing detection variability among used platforms. Only data collected

212 during sea state condition equal or less than 4 (Beaufort scale) were used in the analysis. This

213 threshold was chosen according to results of Cominelli et al. (2016) where it has been

214 demonstrated that sea state condition has no influence on sighting distance of this species from 
215 ferries, up to sea state greater than four (Beaufort scale). Another factor that has been considered

216 is the variability of observation platforms, which directly impacts heights of observers on the sea

217 level. Different ferries have been involved in data collection, with height of command decks

218 ranging from 12-29meters and speed ranging from 14-29 knots. Ferries were categorized into 3

219 types, according to height of command deck and average speed: Type I ferries included ferries

220 with height of command deck between 12 and $15 \mathrm{~m}$ and average speed 17.3 knots, Type II

221 ferries with 20-22 m and average speed 23.1 knots command deck heights and Type III ferries

222 with heights between 25 and $29 \mathrm{~m}$ and average speed 22.3 knots. Distance sampling analysis has

223 been performed using the package RDistance (version2.1.3) in R (version 3.6.1). The objective

224 of the analysis was to compute the Effective Strip Width (ESW) separately for each different

225 type of ferry used, in order to take into account differences occurring among different

226 observation platforms (Virgili et al., 2019). All sightings collected during the sampling period

227 have been used for the assessment of the ESWs. Radial distances and angles between sightings

228 and ferry heading were used to compute perpendicular distances. For each type of ferry three

229 different detection functions have been tested, with zero or one adjustment: Half normal,

230 Uniform and Hazard rate. In order to choose the optimal detection function, the 6 obtained AIC

231 have been compared and the best model has been chosen according to lowest AIC value. Finally,

232 we tested the effect of group size as a covariate and incorporate it in the final chosen model,

233 according to lowest AIC value.

234

235 Density of fin whales (D) was then computed as

236

$$
D_{t}=\frac{n_{t}}{2 E S W_{\text {type }} l_{t}} * 100
$$

237 Where

$238 t=$ transect

$239 n_{t}=$ number of animals observed along the transect

$240 \mathrm{ESW}_{\text {type }}=\mathrm{ESW}$ as computed for the type of ferry used for that transect

$241 l_{t}=$ total length of the transect

242

243 Sampling frequency varied among routes, from weekly to monthly, depending on ferry company

244 schedule. Spearman's rank correlation coefficient test was used in order to assess correlation

245 among densities computed from transects of the same transect group and sampled within the 
246 same day or consecutive days, or within the same week (considered as a minimum of 7 days

247 separating two consecutive trips). Transects were considered as correlated when Spearman's $\rho$

248 value was $>0.5$. For routes where transects were found to be correlated, one among the two

249 consecutive transects was randomly kept. The correlation process has been done stepwise, first

250 starting on the same day scale, then performing the analysis on the retained dataset (without

251 transects discarded in the previous step) on the weekly scale. The same threshold for the

252 correlation was applied to all steps.

253

254

255

Fin whale groups

256

As school size can be an indicator of whale feeding success or food availability (Littaye et al.,

257

2004), frequency distribution of size of groups was inspected at both scales (global and sub-area

258

scale). For this analysis, group size is defined by the total number of individuals sighted at the

259

same time after the first detection (used for the distance sampling parameters) in the area covered

260

by the observer. Group sizes have been classified into 4 categories: "single" (for sighting with

261

only 1 individual), "pair" (2 individuals), "small group" (3 to 5 individuals) and "large group"

262 (more than 5 individuals).

$263 \chi^{2}$ test were used to compare frequency distribution of group sizes among years, at both scales,

264 as well as differences in the four sub-areas.

265

266 Summer presence

267 Average density for the entire basin (computed using the entire dataset of $D_{t}$ ) and for the four

268 sub-areas (computed as the average of the $\mathrm{D}_{\mathrm{t}}$ falling within the same subarea) were used as an

269 index to highlight patterns in the summer presence of the species for the overall considered

270 period. Kruskal-Wallis tests with post-hoc Dunn's tests were performed to find statistical

271 differences among different years and among different sub-areas.

272 Generalized Additive Models (GAM) (Hastie \& Tibshirani, 1986) were used to inspect the role

273 of the year in describing the trends of the species presence, at all considered geographical scales.

274 While linear regression methods are usually applied for inspecting trends in distribution, GAMs

275 were preferred to linear models for their ability to deal with highly non-linear and non-

276 monotonic relationships (Guisan, Edwards \& Hastie, 2002), thus expected to better catch the 
277 complex trends in presence distribution known for this region (Cominelli et al., 2016; Morgado 278 et al., 2017).

279 GAMs were fitted with a tweedie distribution, applying REML method for smoothness of terms 280 and adding ESW as an offset. The only explanatory variable was the year, the scale parameter 281 was set to -1.0 and gamma to 1.4 to deal better with overdispersion in the data (Wood, 2006)).

282 Final GAM formula is

$$
D=s(\text { year }, k=n)
$$

284

285

Knots were restricted to 7, as the shortest continuous time series available (for the WP and SEP 286 regions, considering gap years).

\section{Results}

289

\section{ESW}

290 During the summer months between 2008 and 2018, 228257.5 km along 1190 transects have 291 been monitored in the Mediterranean Sea. After considering the $30 \%$ of the maximum length 292 threshold values, 1146 transects were kept for the analyses (Table 1).

2931705 sightings have been collected during the entire period and among these 1687 could be used 294 for computing ESWs. No fin whale sightings were recorded in the AD sub area, so no further 295 analysis was possible for this sub area.

296 Based on AIC, for all the three groups of ferries a Hazard rate model with no adjustment terms

297 was chosen as the final detection function. For all the three groups adding group size as a

298 covariate resulted in a lower AIC value. More details of distance sampling analysis are reported 299 in Supl_2_Distance.

300 Final ESWs were set respectively $1858 \mathrm{~m}$ for Type I ferries, $2657 \mathrm{~m}$ for Type II e $1113 \mathrm{~m}$ for 301 Type III.

302

303 Correlation between trips

304 Table 2 summarizes the results of the Spearman's rank correlation coefficient for the different 305 transect groups. Transect groups missing from the table were not tested as there were not enough 306 occurrences for the test or there was a 0 inflation (due to a low number of sightings). Transects 
307 performed within the same day or consecutive days were correlated (Spearman's correlation

308 index > 0.5) along the SB, NC and SC transect groups, but not in the LG and CTCV groups.

309 However, since the test is not significant for these groups, we decided to consider transects

310 performed on the same day as correlated, following a precautionary approach. For the NLB and

311 SLB transect groups, Spearman's correlation index is not calculated as not enough data were

312 available, while for the NB, TAJ and TI there were only few cases of transects performed within

313 the same day.

314 Weekly correlation was not found along any transect group. Following the correlation tests and

315 not considering the N_AP and S_AP transects, 350 transects were eliminated so the final dataset

316 consists of 796 transects.

317

318 Fin whale Group sizes

319 Only sightings from transects selected after checking for correlation were used to inspect group

320 size of the species. The final dataset accounts for 1154 sightings, for a total of 1608 fin whale

321 sighted. More than $72 \%$ of sightings were of single individuals $(n=834), 21 \%$ of pairs $(n=245)$,

322 and the remaining $7 \%$ of groups of three or more individuals ( $n=69$ and $n=6$ for "small group"

323 and "large groups" respectively). The main outlier is represented by a sighting of 12 individuals,

324 occurred on 05/06/2015 along the E_CVBA transect and representing a very sparse group of

325 animals.

$326 \chi^{2}$ test for the entire study area indicated a significant difference in group distribution among

327 years $\left(\chi^{2}=66.038, \mathrm{df}=30, \mathrm{p}\right.$-value $\left.=0.0001613\right)$. Overall, single individuals were the main type

328 of encounter, followed by “pair”. Small groups were detected more constantly only in 2012,

3292013 and 2015 and were rare in 2009, 2010 and 2018; large groups were encountered only in

3302013,2015 and 2018.

331

332 Figure 3 represents the frequency distribution of group size by sub-areas and by years. Small and

333 large groups of fin whales were frequently sighted only in the PEL or in the WP, in 2012, 2013

334 and 2015, while no groups occurred in the rest of the basin.

$335 \chi^{2}$ test found a significative difference among years in the PEL $\left(\chi^{2}=53.241, \mathrm{df}=30, \mathrm{p}\right.$-value $=$

336 0.005579), while no differences was found in the two other sub-areas $\left(\chi^{2}=18.128, \mathrm{df}=18, \mathrm{p}\right.$ -

337 value $=0.4473$ for the WP and $\chi^{2}=4.9524, \mathrm{df}=5, \mathrm{p}$-value $=0.4217$ for the SEP). 


\section{Summer presence}

340 Overall density in the western basin for the entire period was 0.30 fin whales per $100 \mathrm{~km}^{2}(95 \%$

341 CI 0.26-0.35); the sub-area scale confirmed the importance of the PEL, where the overall D

342 recorded was $0.35(95 \%$ CI $0.30-0.41)$. Highest D was recorded in the WP area $(0.46 ; 95 \%$ CI

$3430.30-0.62)$ while lowest value characterized the SEP $(0.01 ; 95 \%$ CI 0.005-0.02). Differences

344 among different sub-areas were statistically significant (KW Kruskal-Wallis chi-squared $=$

$34591.926, \mathrm{df}=2, \mathrm{p}$-value $<2.2 \mathrm{e}-16$ ), confirmed by the Dunn's post-hoc test.

346

347 Yearly D values for the overall region and for the three sub-areas are visualized in Figure 4 and 348 reported in Table 3.

349 Kruskal-Wallis post hoc test for differences among years, statistically confirmed the interannual

350 variability (Kruskal-Wallis chi-squared $=74.51, \mathrm{df}=10, \mathrm{p}$-value $=5.926 \mathrm{e}-12)$. Dunn's test

351 highlighted some years as being very different from the others (Table 4). In particular 2012,

3522013 and 2015, showed highest values of the considered period, with 2013 being the most

353 anomalous year, differing from 8 other years. Looking at the poorest years, 2008 and 2014

354 emerge, though for 2008 it must be stressed that the low survey coverage is most probably

355 affecting this result. .

356 Concerning the sub-area analysis, no differences were found among years in the SEP area

357 (Kruskal-Wallis chi-squared $=9.1586, \mathrm{df}=6, \mathrm{p}$-value $=0.1649$ ), while interannual differences

358 were confirmed for the PEL (Kruskal-Wallis chi-squared $=59.644$, $\mathrm{df}=10$, p-value $=4.236 \mathrm{e}-09$ )

359 and for the WP area (Kruskal-Wallis chi-squared $=17.937, \mathrm{df}=6, \mathrm{p}$-value $=0.006393$ ).

360 In PEL, the most anomalous years appeared to be 2015. Poorest years match to the ones

361 observed for the entire region, though for 2008 we shall always consider the difference in

362 sampling effort. Similarly, in 2013 and 2015 we find the same anomalous peaks shown for the

363 entire basin. In this sub area 2010,2012 and 2017 can be considered as reference years, not being

364 different from any other year (Table 5a). For the WP area, 2015 emerges as the richest year,

365 though not being different from any other years, while 2017 is the lowest density year and

366 represent an anomaly compared to 2012 and 2013, as confirmed by Dunn's test (Table 5b). This

367 sub area is characterized by high variability of D values, but the overall pattern of D is similar to

368 the one of the PEL sub region. 
370 Estimated trends in species presence at all considered spatial scales are shown in Figure 5. For

371 the Western Mediterranean basin, it is possible to summarize the trend into 3 separated periods:

372 a positively increasing trend from 2008 up to year 2013, with the predicted density values

373 increasing over $60 \%$ in this period, then a slightly decreasing trend up to 2016 and finally a

374 relatively stable period during the last two considered years. A similar pattern is found in the

375 Pelagos Sanctuary area, where after the first period with the increasing trend ending with a peak

376 in 2012-2013, a relatively stable period is found, with a new slowly increasing trend in the end.

377 The Western Pelagos and the South Eastern Pelagos area showed an almost linear negative trend.

378 Gaps in the dataset for these two sub areas, as well as a lower coverage though, must be taken

379 into account in the analysis of these trends. While for the WP and SEP sub areas, the year has a

380 good ability to explain deviance of the dataset (deviance explained is $15.1 \%$ and $33.2 \%$

381 respectively for the WP and SEP sub regions, Table 6a), lower values are found for the PEL sub

382 region (deviance explained 2.39\%). Being this subregion the most covered spatially and

383 temporally, we tried to investigate possible factors affecting variability other than the year. We

384 then fitted the GAM model for this sub region adding the transect group as variables in the

385 model. By adding the routes, the new model has a deviance explained of $44.1 \%$. Particularly, the

386 easternmost routes, namely the Livorno-Bastia, Livorno-Golfo Aranci e Savona-Bastia act as

387 significatively contributing factors (Table $6 \mathrm{~b}$ ).

\section{Discussion}

389 The Marine Strategy Framework Directive aims to achieve Good Environmental Status (GES) of

390 the EU's marine waters by 2020 and to protect the resources upon which marine-related

391 economic and social activities depend. Population abundance is one of the criteria (D1C2)

392 identified to assess progress towards the GES, and specifically baleen whale trends in

393 abundance, is one of the criteria for assessing GES under the biodiversity descriptor D1.

394 Monitoring of fin whale abundance is also required for the assessment of the status of the species

395 for conservation purposes (e.g. IUCN assessment, conservation objectives under the Pelagos

396 Sanctuary, ACCOBAMS agreement, Barcelona Convention). It is widely recognized that long

397 dataset are needed for reliable trend estimation, and 10 years have been identified as a suitable

398 interval for the short-term trend assessment (Palialexis et al., 2019). Recurrent monitoring of 
399 large areas though is difficult to achieve, for logistic and furthermore cost related factors. In this

400 work, we present the results from a long-term monitoring project, which allowed for the creation

401 of a 10year dataset on fin whale presence in the Western Mediterranean. Data have been

402 collected using ferries as platform of opportunity and following a dedicated research protocol,

403 ensuring data consistency. Effectiveness of this ferries fleet has been previously demonstrate in

404 monitoring of marine litter (Arcangeli et al., 2020), sea turtles (Arcangeli et al., 2019) and

405 cetacean species (Campana et al., 2015; Arcangeli, Campana \& Bologna, 2017; Morgado et al.,

406 2017). In this work we further addressed possible biases arising from sampling methodologies, in

407 several steps of the analysis framework. Ninety two percent of our dataset has been collected

408 with sea state conditions equal or less than three (Beaufort scale); considering that a threshold of

4094 can be applied for ensuring highest sightability of this species from the considered platforms

410 (Cominelli et al., 2016), our dataset can be considered robust to weather conditions. Though

411 different types of ferries have been used in the analysis, the protocol foresees the use of a restrict

412 range of ferry types as platform of observation, avoiding for example fast ferries or cruise ships.

413 Ferries operating along the considered routes do not vary annually, neither does the effort or the

414 survey protocol, so eventual bias are consistent along the years, thus not influencing the overall

415 observed trend. To further consider possible influences related to differences in platform used,

416 ferries have been treated separately for computing ESWs, based on both height of command

417 deck and average speed. Considering that the analysis is species-specific and that the sea state

418 threshold applied guarantees robustness towards this parameter, the computation of ESW

419 specifically according to platform type allows for the direct comparison of different surveys

420 (Hedley \& Buckland, 2004; Virgili et al., 2019).

421

422 Fin whale summer presence in the Western Mediterranean basin is characterized by a strong 423 interannual variability. The analysis of density indexes, performed thanks to a synoptic data 424 collection over the western Mediterranean basin, suggests variability between high density (rich) 425 years, as 2012, 2013 and 2015 and low density years, 2014 specifically, as for 2008 a lower 426 research effort likely contribute to low density.

427 Looking at intra-basin presence and distribution, no sighting of the species occurred during the 428 summertime over the considered period in the Adriatic Sea. While the species was previously 
429 sighted in the Adriatic Region, these sightings must be considered as occasional for the species

430 (Notarbartolo di Sciara et al., 2003; Lipej, Dulčić \& Kryštufek, 2004).

431 The Pelagos Sanctuary for marine mammals, established in 2002 in the northern area of the

432 Western Mediterranean basin (Notarbartolo-di-Sciara et al., 2008), is confirmed as a very

433 important area for this species, hosting high density values during summertime. The interannual

434 variability is also present in this sub-area, as already found in previous works (Panigada et al.,

435 2005; Cominelli et al., 2016; Morgado et al., 2017). The analysis of this biggest dataset

436 strengthens the importance of considering this variability in planning monitoring on a yearly

437 basis. The Western Pelagos sub-area emerged as an important area for the species (Arcangeli,

438 Campana \& Bologna, 2017). Density values were comparable and even higher than the ones

439 recorded in the Pelagos Sanctuary sub-area. Values recorded here also showed the highest

440 variability. Acoustic studies and stable isotope analysis (Castellote, Clark \& Lammers, 2012a,b;

441 Giménez et al., 2013), indicate the presence in the Mediterranean basin, and particularly in the

442 area South of Spain, of another subpopulation of fin whales, the NENA subpopulation (North

443 East North Atlantic fin whales), seasonally travelling here from the North Atlantic Ocean.

444 Distributional range of this sub-populations is under debate, but an extension of the range of

445 penetration of individuals from the Atlantic to the Provençal basin has been recently

446 demonstrated (Giménez et al., 2013).The highest variability recorded in the Western Pelagos

447 sub-area can then be due to the mixing of the NENA and the MED subpopulation, occurring

448 when the NENA fin whales travel further east than their usual distribution. It also needs to be

449 underlined that the Western Pelagos together with the Pelagos Sanctuary sub-areas are

450 recognized as an Important Marine Mammal Area for the Mediterranean sea (Agardy et al.,

451 2019).

452 In the Pelagos Sanctuary sub-area, density values were found to be correlated at a daily scale, but

453 no correlation was found at a weekly scale in the whole study area. This can be interpreted by the

454 species not being stable in the area, probably following a patchier distribution of preys all around

455 the basin. While a clear interpretation on whale movements is not possible through our dataset,

456 still it gives an indication on the irregular presence of animals, consequently evidencing the need

457 to integrate datasets coming from surveys conducted on a short period of time, which may lead

458 to an under-estimation of results. Repeated surveys along fixed transects better catch the 
459 temporal changes in distribution of the species, integrating the results obtained by more localized

460 surveys which focus on spatial analysis of species presence and habitat preferences.

461 The species is not absent from the South Eastern Pelagos sub-area, where rare but still yearly

462 regular sightings were recorded. Specifically, localized hot-spots are known to occur in this basin

463 during particular time of the year (Canese et al., 2006; Pace et al., 2019) while, in general, the

464 area can be seen as a traveling area among different sub-areas. The FLT Med Network is the first

465 and only recurring monitoring of this sub-area. Recurrent monitoring in the sub-area could help

466 integrating short-term surveys results, especially when the fail to record species presence due to

467 limited effort in space and time.

468

469 Looking at interannual variability at sub-area scale, some years emerge as particularly

470 anomalous both in the Pelagos Sanctuary and in the Western Pelagos sub-area, though, in the

471 latter, the smaller size of the dataset must be taken into account for carefully interpreting results.

472 Still, it should be underlined that in 2012, 2013 and 2015 density values were higher than

473 average in both sub-areas. These results confirm the pattern highlighted by Morgado et al.

474 (2017), though a strong difference in the two analyses for the year 2013 is found. In our analysis,

4752013 emerges as the second richest year of the entire dataset (Figure 4), while was classified as a

476 poorer year than 2012 in the previous analysis. This difference can be due to the lack of data

477 from the Tyrrhenian area, covered in this work by the transects LGA and E_CVBA, which were

478 not considered in the previous study. The intermittent blooming area of the Bonifacio Gyre

479 (D'Ortenzio \& Ribera d'Alcalà, 2009) can represent an alternative feeding ground for the species

480 that can concentrate also here, rather than in the usual areas in the Western portion of the basin

481 (Arcangeli et al., 2014). This result stresses the importance of a complete coverage of the basin

482 when looking for trends of species.

483

484 While the species is most commonly sighted as single individuals or pairs (Notarbartolo di Sciara 485 et al., 2003; Arcangeli, Marini \& Crosti, 2012, and results from this work), particularly favorable 486 ecosystem conditions, leading to the presence of food patches, can lead to the presence of groups 487 (Littaye et al., 2004; Aïssi et al., 2008). In our analysis, richest years, indicated by the highest 488 density values, are also characterized by the presence of small groups and large groups in the 489 Pelagos Sanctuary and Western Pelagos sub-areas. Only single animals were sighted on the 
490

491 492

493

494

495

496

497

498

499

500

501

502

503

504

505

506

507

508

509

510

511

512

513

\section{Conclusions}

515 The FLT Med Network, operating since 2008 in the Western Mediterranean Basin and in the

516 Adriatic and Ionian region, is the only recurring monitoring occurring in the basin. The use of

517 ferries as a platform of opportunity and a strong scientific protocol shared among all institutions,

518 allow for a consistent data collection. Repeatability of surveys as well as the possibility of

519 surveying areas usually difficult to reach, allowed for the collection of a unique dataset during 
520 the entire year. Moreover, the network is now expanding in Spain with new routes covering the

521 recently established SPAMI Spanish corridor and in the Gibraltar Strait, and further in the

522 southern Mediterranean basin, allowing to include already known important areas such as the

523 Lampedusa and Malta areas.

524 The importance of datasets collected by platforms of opportunity has already been recognized

525 within the MSFD and specifically for the floating marine litter monitoring in high sea areas

526 (Arcangeli et al., 2020) and more recently for the sea turtles' assessment. The yearly monitoring 527 and the GAM approach for the definition of trends, allow for the interpretation of these results 528 within the framework of the MSFD and HD. Looking at the complex trends, we can distinguish 529 within our sampling periods the two reference periods indicated by the HD, namely 2007-2012 530 as the first reporting period and 2013-2018 as the second reporting period. Keeping the spatial 531 scale addressed by the MFSD, equal to the Western Mediterranean Basin, it is possible to 532 confirm an increasing trend followed by a negative trend, with a $-40 \%$ percentage variation from 5332012 to 2018 . On the other hand, the interannual analysis allowed to highlight reference years 534 that can be used as a baseline for the definition of the trend of the following years. This is 535 another approach that has been suggested for the evaluation of trends of population presence, 536 given the lack of abundance estimates in past years and the difficulties in conducting large scale 537 surveys. We highlight 2010 and 2016 as reference years for the evaluation of the following 538 years, being those years the less different from the others. Looking at these reference years, after 539 a variation $-43 \%$ (from 2010 to 2011 ), matching with the negative trend previously highlighted,

540 the overall variation for the entire period is $-6 \%$, indicating a limited negative trend for this area.

541 Our results also highlighted the importance of considering different spatial scales when looking

542 at species presence and distribution, together with the need to specifically address peculiar areas

543 known to be important for the species.

545 An integrated approach foreseeing both large basin wide scale surveys and yearly monitoring, 546 would allow a better interpretation of results. Indeed, the large basin wide scale surveys 547 conducted every 6 or 10 years would allow for more accurate abundance estimates over the 548 whole range of the species, while the results from yearly monitoring with ferries could help 549 correct and interpret the large scale surveys, adding the information on interannual variability, 550 and helping in addressing abundance estimates into rich or poor years. Our work not only 
551 confirmed some previous findings about species presence in the area but also enlarged current

552 knowledge of species presence in other areas previously poorly investigated.

553

\section{Acknowledgements}

555 We wish to thank all the ferry companies who are thoughtfully collaborating with us in the FLT

556 Med Network, and specifically the Corsica Sardinia Ferries, Grimaldi Lines, Minoan and

557 Tirrenia. We are particularly thankful to Cristina Pizzuti (CSF), Rosa Cappuccio (Grimaldi) and

558 all the staff of the ferries for the constant and kind support on all logistic aspects. This work

559 would not be possible without all the students, volunteers and researchers who professionally and

560 passionately collect data onboard.

561

562

\section{References}

564 Agardy T, Cody M, Hastings S, Hoyt E, Nelson A, Tetley M, Notarbartolo di Sciara G. 2019.

565

566

567

568

569

570

571

572

573

574

575

576

577

578

579

580

Looking beyond the horizon: An early warning system to keep marine mammal information relevant for conservation. Aquatic Conservation: Marine and Freshwater Ecosystems 29:71-83. DOI: 10.1002/aqc.3072.

Aïssi M, Arcangeli A, Crosti R, Daly Yahia MN, Loussaief B, Moulins A, Pellegrino G, Rosso M, Tringali LM, Tepsich P. 2015. Cetacean occurrence and spatial distribution in the central Mediterranean Sea using ferries as platform of observation. Russian Journal of Marine Biology 41:343-350. DOI: 10.1134/S1063074015050028.

Aïssi M, Celona A, Comparetto G, Mangano R, Würtz M, Moulins A. 2008. Large-scale seasonal distribution of fin whales (Balaenoptera physalus) in the central Mediterranean Sea. Journal of the Marine Biological Association of the United Kingdom 88:1253-1261. DOI: $10.1017 / \mathrm{S} 0025315408000891$.

Arcangeli A, Campana I, Bologna MA. 2017. Influence of seasonality on cetacean diversity, abundance, distribution and habitat use in the western Mediterranean Sea: Implications for conservation. Aquatic Conservation: Marine and Freshwater Ecosystems 27:995-1010. DOI: $10.1002 /$ aqc. 2758 .

Arcangeli A, David L, Aguilar A, Atzori F, Borrell A, Campana I, Carosso L, Crosti R, Darmon 
581

582

583

584

585

586

587

588

589

590

591

592

593

594

595

596

597

598

599

600

601

602

603

604

605

606

607

608

609

610

611

$$
\text { G, Gambaiani D, Di-Méglio N, Di Vito S, Frau F, Garcia Garin O, Orasi A, Revuelta O, }
$$
Roul M, Miaud C, Vighi M. 2020. Floating marine macro litter: Density reference values and monitoring protocol settings from coast to offshore. Results from the MEDSEALITTER project. Marine Pollution Bulletin 160:111647. DOI: 10.1016/j.marpolbul.2020.111647.

Arcangeli A, Maffucci F, Atzori F, Azzolin M, Campana I, Carosso L, Crosti R, Frau F, David L, Di-Méglio N, Roul M, Gregorietti M, Mazzucato V, Pellegrino G, Giacoletti A, Paraboschi M, Zampollo A, de Lucia GA, Hochscheid S. 2019. Turtles on the trash track: Loggerhead turtles exposed to floating plastic in the Mediterranean Sea. Endangered Species Research 40:107-121. DOI: 10.3354/ESR00980.

Arcangeli A, Marini L, Crosti R. 2012. Changes in cetacean presence, relative abundance and distribution over 20 years along a trans-regional fixed line transect in the Central Tyrrhenian Sea. Marine Ecology 34:112-121.

Arcangeli A, Orasi A, Carcassi SP, Crosti R. 2014. Exploring thermal and trophic preference of Balaenoptera physalusin the central Tyrrhenian Sea: a new summer feeding ground? Marine Biology 161:427-436.

Azzellino A, Airoldi S, Lanfredi C, Podestà M, Zanardelli M. 2017. Cetacean response to environmental and anthropogenic drivers of change: Results of a 25-year distribution study in the northwestern Mediterranean Sea. Deep Sea Research Part II: Topical Studies in Oceanography 146:104-117. DOI: 10.1016/J.DSR2.2017.02.004.

Azzolin M, Arcangeli A, Cipriano G, Crosti R, Maglietta R, Pietroluongo G, Saintingan S, Zampollo A, Fanizza C, Carlucci R. 2020. Spatial distribution modelling of striped dolphin ( Stenella coeruleoalba ) at different geographical scales within the EU Adriatic and Ionian Sea Region, central-eastern Mediterranean Sea . Aquatic Conservation: Marine and Freshwater Ecosystems:1-14. DOI: 10.1002/aqc.3314.

Bérubé M, Aguilar A, Dendanto D, Larsen F, Notarbartolo di Sciara G, Sears R, Sigurjonsson J, Urban R. J, Palsboll PJ. 1998. Population genetic structure of North Atlantic, Mediterranean Sea and Sea of Cortez fin whale, Balaenopera physalus (Linnaeus 1758): analysis of mitocondrial and nuclear loci. Molecular Ecology 7:585-599.

Brown MR, Corkeron PJ, Hale PT, Schultz KW, Bryden MM, Brown MR, Corkeron PJ, Hale PT, Schultz KW, Bryden MM. 2016. Evidence for a Sex-Segregated Migration in the 
612 Humpback Whale ( Megaptera novaeangliae ) Stable URL :

613 http://www.jstor.org/stable/50160 Linked references are available on JSTOR for this

614 article : Evidence for a sex-segregated migration in the humpback wha. 259:229-234.

615 Campana I, Crosti R, Angeletti D, Carosso L, David L, Di-M??glio N, Moulins A, Rosso M,

616 Tepsich P, Arcangeli A. 2015. Cetacean response to summer maritime traffic in the Western

617 Mediterranean Sea. Marine Environmental Research 109:1-8.

618 Canese S, Cardinali A, Fortuna CM, Giusti M, Lauriano G, Salvati E, Greco S. 2006. The first 619 identified winter feeding ground of fin whales (Balaenoptera physalus) in the Mediterranean 620 Sea. Journal of the Marine Biological Association of the United Kingdom 86:903-907.

621 Castellote M, Clark CW, Lammers MO. 2012a. Fin whale (Balaenoptera physalus) population 622 identity in the western Mediterranean Sea. Marine Mammal Science 28:325-344.

623 Castellote M, Clark CW, Lammers MO. 2012b. Acoustic and behavioural changes by fin whales 624 (Balaenoptera physalus) in response to shipping and airgun noise. Biological Conservation $625 \quad 147: 115-122$.

626 Cominelli S, Moulins AAA, Rosso M, Tepsich P. 2016. Fin whale seasonal trends in the Pelagos 627 Sanctuary, Mediterranean Sea. Journal of Wildlife Management 80:490-499. DOI: $628 \quad 10.1002 /$ jwmg.1027.

629 Coomber FG, D’Inc?? M, Rosso M, Tepsich P, Notarbartolo di Sciara G, Moulins A. 2016. 630 Description of the vessel traffic within the north Pelagos Sanctuary: Inputs for Marine 631 Spatial Planning and management implications within an existing international Marine 632 Protected Area. Marine Policy 69:102-113. DOI: 10.1016/J.MARPOL.2016.04.013.

633 Correia AM, Tepsich P, Rosso M, Caldeira RMA, Sousa-Pinto I. 2015. Cetacean occurrence and 634 spatial distribution: Habitat modelling for offshore waters in the Portuguese EEZ (NE 635 Atlantic). Journal of Marine Systems 143:73-85. DOI: 10.1016/j.jmarsys.2014.10.016.

D’Ortenzio F, Ribera d'Alcalà M. 2009. On the trophic regimes of the Mediterranean Sea: a satellite analysis. Biogeosciences 6:139-148.

David L, Alleaume S, Guinet C. 2011. Evaluation of the potential of collision between fin whales and maritime traffic in the north-western Mediterranean Sea in summer, and mitigation solutions. Journal of Marine Animals and Their Ecology 4:17-28.

Di-Méglio N, Campana I. 2017. Floating macro-litter along the Mediterranean French coast: Composition, density, distribution and overlap with cetacean range. Marine Pollution 
643

644

645

646

647

648

649

650

651

652

653

654

655

656

657

658

659

660

661

662

663

664

665

666

667

668

669

670

671

672

673

Bulletin 118:155-166. DOI: 10.1016/j.marpolbul.2017.02.026.

Druon J-N, Panigada S, David L, Gannier A, Mayol P, Arcangeli A, Cañadas A, Laran S, Di Méglio N, Gauffier P. 2012. Potential feeding habitat of fin whales in the western Mediterranean Sea: an environmental niche model. Marine Ecology Progress Series 464:289-306.

Forcada J, Aguilar A, Hammond P, Pastor X, Aguilar R. 1996. Distribution and abundance of fin whales (Balaenoptera physalus) in the western Mediterranean sea during summer. Journal of Zoology 238:23-34.

Forcada J, Notarbartolo Di Sciara G, Fabbri F. 1995. Abundance of fin whales and striped dolphins summering in the Corso-Ligurian Basin. Mammalia 59:127-140.

Fossi MC, Coppola D, Baini M, Giannetti M, Guerranti C, Marsili L, Panti C, de Sabata E, Ciò S. 2014. Large filter feeding marine organisms as indicators of microplastic in the pelagic environment: the case studies of the Mediterranean basking shark (Cetorhinus maximus) and fin whale (Balaenoptera physalus). Marine Environmental Research 100:17-24.

Gannier A. 2006. Le peuplement estival de cétacés dans le Sanctuaire Marin Pelagos (Méditerranée nord-occidentale): distribution et abondance. Mammalia 70:17-27.

Geijer CKA, Notarbartolo di Sciara G, Panigada S. 2016. Mysticete migration revisited: are Mediterranean fin whales an anomaly? Mammal Review 46:284-296. DOI: 10.1111/mam.12069.

Giménez J, Gómez-Campos E, Borrell A, Cardona L, Aguilar A. 2013. Isotopic evidence of limited exchange between Mediterranean and eastern North Atlanticfin whales. Rapid Communications in Mass Spectometry 27:1801-1806.

Guisan A, Edwards TC, Hastie T. 2002. Generalized linear and generalized additive models in studies of species distributions: setting the scene. Ecological Modelling 157:89-100.

Hastie T, Tibshirani R. 1986. Generalized Additive Models. Statistical Science 1:297-318. Hedley SL, Buckland ST. 2004. Spatial Models for Line Transect Sampling. Journal of Agricultural, Biological, and Environmental Statistics 9:181-199.

ISPRA. 2016. Agreement "Fixed Line Transect monitoring using ferries as platform of observation for marine mega and macro fauna and main threats". Technical annex Imonitoring protocol for cetaceans and sea turtles. pp.19.

Kinzey D, Gerrodette T. 2003. Distance measurements using binoculars from ships at sea: 
674

675

676

677

678

679

680

681

682

683

684

685

686

687

688

689

690

691

692

693

694

695

696

697

698

699

700

701

702

703

704

accuracy, precision and effects of refraction. Journal of Cetacean Research and Management 5:159-171.

Kiszka J, Macleod K, Van Canneyt O, Walker D, Ridoux V. 2007. Distribution, encounter rates, and habitat characteristics of toothed cetaceans in the Bay of Biscay and adjacent waters from platform-of-opportunity data. ICES Journal of Marine Science 64:1033-1043.

Laran S, Joiris C, Gannier A, Kenney RD. 2010. Seasonal estimates of densities and predation rates of cetaceans in the Ligurian Sea, northwestern Mediterranean Sea: An initial examination. Journal of Cetacean Research and Management 11:31-40.

Laran S, Pettex E, David L, Dorémus G, Falchetto H, Monestiez P, Van Canneyt O. 2017. Seasonal distribution and abundance of cetaceans within French waters- Part I: The NorthWestern Mediterranean, including the Pelagos sanctuary. Deep Sea Research Part II: Topical Studies in Oceanography 141:20-30. DOI: 10.1016/J.DSR2.2016.12.011.

Lipej L, Dulčić J, Kryštufek B. 2004. On the occurrence of the fin whale (Balaenoptera physalus) in the Northern Adriatic. Journal of the Marine Biological Association of the United Kingdom 84:861-862.

Littaye A, Gannier A, Laran S, Wilson JPF. 2004. The relationship between summer aggregation of fin whales and satellite-derived environmental conditions in the northwestern Mediterranean Sea. Remote Sensing of Environment 90:44-52.

Marsili L, Focardi S. 1996. Organochlorine levels in subcutaneous blubber biopsies of fin whale (Balaenoptera physalus) and striped dolphin (Stenella coeruleoalba) from the Mediterranean Sea. Environmental Pollution 91:1-9.

Mayot N. 2015. Interannual variability of the Mediterranean trophic regimes. :14941-14980. DOI: $10.5194 /$ bgd-12-14941-2015.

Morgado C, Martins A, Rosso M, Moulins A, Tepsich P. 2017. Fin Whale Presence and Distribution in the Pelagos Sanctuary: Temporal and Spatial Variability Along 2 Fixed-Line Transects Monitored in 2009-2013. International Journal of Marine and Environmental Sciences 1:1-14.

Notarbartolo-di-Sciara G, Agardy T, Hyrenbach D, Scovazzi T, Van Klaveren P. 2008. The Pelagos Sanctuary for Mediterranean marine mammals. Aquatic Conservation: Marine and Freshwater Ecosystems 18:367-391. DOI: 10.1002/aqc.855.

Notarbartolo di Sciara G, Castellote M, Druon J-N, Panigada S. 2016. Fin Whales, Balaenoptera 
705

706

707

708

709

710

711

712

713

714

715

716

717

718

719

720

721

722

723

724

725

726

727

728

729

730

731

732

733

734

735

physalus: At Home in a Changing Mediterranean Sea? Advances in Marine Biology 75:75101. DOI: 10.1016/BS.AMB.2016.08.002.

Notarbartolo di Sciara G, Zanardelli M, Jahoda M, Panigada S, Airoldi S. 2003. The fin whale Balaenoptera physalus (L 1758) in the Mediterranean Sea. Mammal Review 33:105-150.

Orsi Relini L, Relini G, Palandri G, Relini M, Garibaldi F, Cima C, Torchia G, Costa C. 1998. Notes on ecology of the mediterranean krill, a mirror of the behaviour of mediterranean fin whales. In: Evans PGH, Parsons ECM eds. European Research on Cetacean. Monaco, 119. Pace DS, Pellegrino G, Cafaro V, Paraboschi M, Silvestri M, Pavan G, Alessi J, Angeletti D, Ardizzone G, Arcangeli A. 2019. An integrated approach for cetacean knowledge and conservation in the central Mediterranean Sea using research and social media data sources. :1302-1323. DOI: 10.1002/aqc.3117.

Palialexis A, Connor D, Damalas D, Gonzalvo J, Micu D, Mitchel I, Korpinen S, Rees AF, Somma F. 2019. Indicators for status assessment of species, relevant to MSFD Biodiversity Descriptor. DOI: 10.2760/282667.

Palsbøll PJ, Bérubé M, Aguilar A, Notarbartolo-Di-Sciara G, Nielsen R. 2004. Discerning between recurrent gene flow and recent divergence under a finite-site mutation model applied to North Atlantic and Mediterranean Sea fin whale (Balaenoptera physalus) populations. Evolution 58:670-675.

Panigada S, Araujo H, Belmont J, Cañadas A, David L, Di-Méglio N, Dorémios G, Gonzalvo J, Holcer D, Laran S, Lauriano G, Le Ravallec C, Paiu RM, Perri M, Pierantonio N, Popov D, Ridoux V, Vazquez JA. 2019. The ACCOBAMS Survey Initiative: The first synoptic survey of the Mediterranean Sea. In: World Marine Mammal Conference WMMC.

Panigada S, Lauriano G, Burt L, Pierantonio N, Donovan G. 2011. Monitoring winter and summer abundance of cetaceans in the Pelagos Sanctuary (Northwestern Mediterranean Sea) through aerial surveys. PLOS ONE 6:e22878.

Panigada S, Lauriano G, Donovan G, Pierantonio N, Cañadas A, Vázquez JA, Burt L. 2017. Estimating cetacean density and abundance in the Central and Western Mediterranean Sea through aerial surveys: Implications for management. Deep-Sea Research Part II: Topical Studies in Oceanography 141:41-58. DOI: 10.1016/j.dsr2.2017.04.018.

Panigada S, Notarbartolo Di Sciara G. 2012. Balaenoptera physalus (Mediterranean subpopulation). 
736 Panigada S, Notarbartolo Di Sciara G, Zanardelli Panigada M, Airoldi S, Borsani JF, Jahoda M.

737

738

739

740

741

742

743

744

745

746

747

748

749

750

751

752

753

754

755

756

757

758

759

760

761

762

763

$$
\text { 2005. Fin whale (Balaenoptera physalus) summering in the Ligurian Sea: distribution }
$$

encounter rate, mean group size and relation to physiographic variables. Journal of Cetacean Research and Management 7:137-145.

Panigada S, Pesante G, Zanardelli M, Capoulade F, Gannier A, Weinrich MT. 2006.

Mediterranean fin whales at risk from fatal ship strikes. Marine Pollution Bulletin 52:12871298.

Peltier HH, Beaufils A, Cesarini C, Dabin W, Dars C, Demaret F, Dhermain F, Doremus G, Labach H, Van Canneyt O, Spitz J. 2019. Monitoring of marine mammal strandings along French coasts reveals the importance of ship strikes on large cetaceans: A challenge for the European Marine Strategy Framework Directive. Frontiers in Marine Science 6:1-6. DOI: 10.3389/fmars.2019.00486.

Sciacca V, Viola S, Pulvirenti S, Riccobene G, Caruso F, De Domenico E, Pavan G. 2016. Shipping noise and seismic airgun surveys in the Ionian Sea: Potential impact on Mediterranean fin whale. Proceedings of Meetings on Acoustics 27. DOI: 10.1121/2.0000311.

Virgili A, Authier M, Boisseau O, Cañadas A, Claridge D, Cole T, Corkeron P, Dorémus G, David L, Di-Méglio N, Dunn C, Dunn TE, García-Barón I, Laran S, Lauriano G, Lewis M, Louzao M, Mannocci L, Martínez-Cedeira J, Palka D, Panigada S, Pettex E, Roberts JJ, Ruiz L, Saavedra C, Santos MB, Van Canneyt O, Vázquez Bonales JA, Monestiez P, Ridoux V. 2019. Combining multiple visual surveys to model the habitat of deep-diving cetaceans at the basin scale: Large-scale modelling of deep-diving cetacean habitats. Global Ecology and Biogeography 28:300-314. DOI: 10.1111/geb.12850.

Wood SN. 2006. Generalized Additive Models: An Introduction with R. Chapman \& Hall/CRC. Wright AJ, Cosentino AM. 2015. JNCC guidelines for minimising the risk of injury and disturbance to marine mammals from seismic surveys: We can do better. Marine Pollution Bulletin 100:231-239. DOI: 10.1016/j.marpolbul.2015.08.045. 
Figure 1

Map of the monitored routes

(1) Toulon (FR) - Alcudia (ES). (2) Toulon (FR) - Ajaccio (FR). (3) Toulon (FR) - Ile rousse (FR).

(4) Toulon (FR) - Bastia (FR). (5) Nice (FR) - Calvi/lle Rousse (FR). (6) Nice (FR) - Bastia (FR).

(7) Savona (IT) - Calvi/lle Rousse (FR). (8) Savona (IT) - Bastia (FR). (9) Livorno (IT) - Bastia

(FR). 10 Livorno (IT) - Golfo Aranci (IT). (11) Civitavecchia (IT) - Barcellona (ES). (12) Catania

(IT) - Civitavecchia (IT). (13) Palermo (IT) - Tunisi (TU). (14) Tunisi (TU) - Civitavecchia (IT).

(15) Cagliari (IT) - Palermo (IT). (16) Ancona (IT) - Patras (GR)

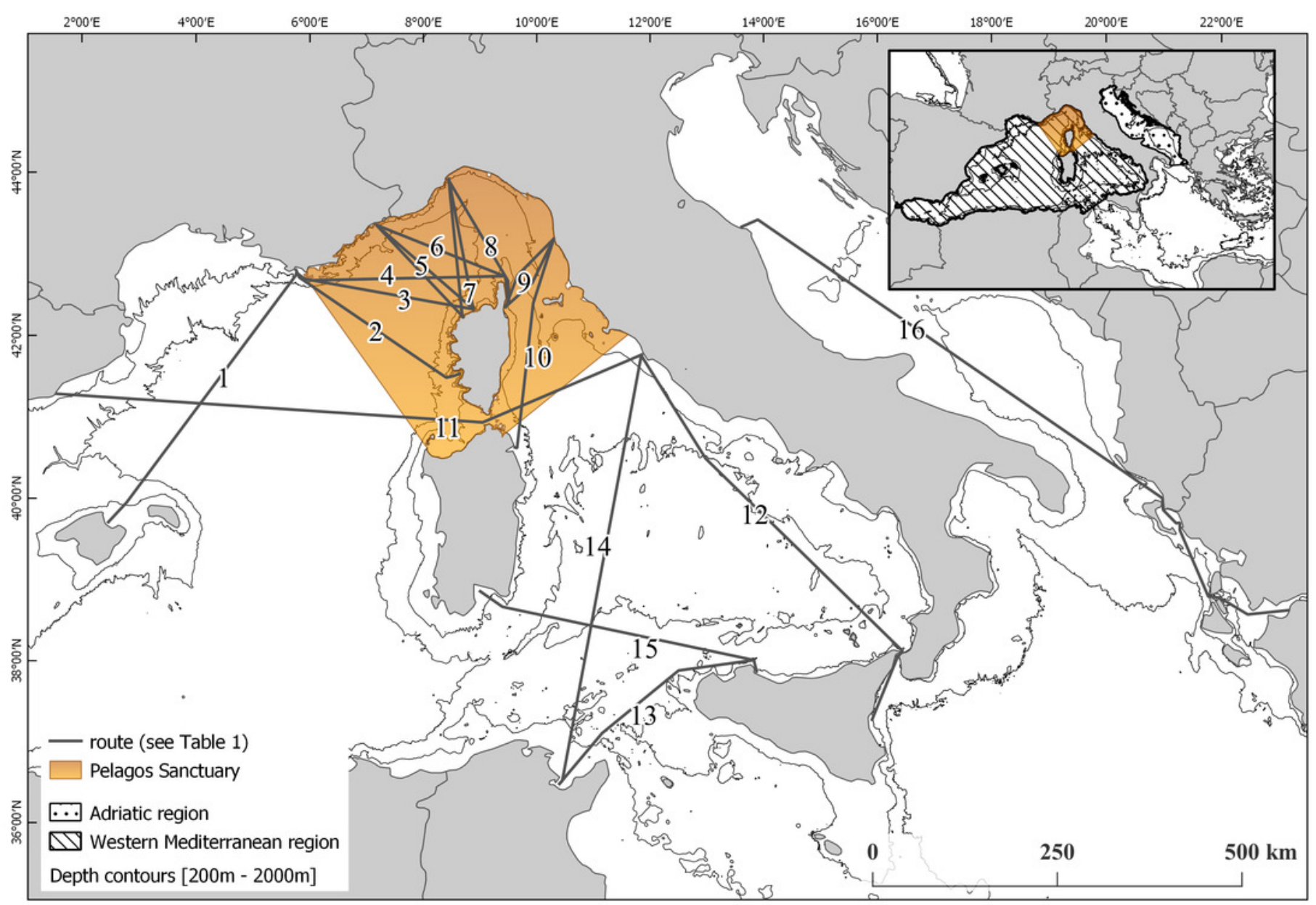


Figure 2

Map of sub-areas and surveyed transects

(WP) Western Pelagos sub-area, including transects from groups TAL and W_CVBA. (PEL) the Pelagos Sanctuary sub-area, including transects from groups TI, TB, NC, NB, SC, SB, N_LB, S_LB, LGA and E_CVBA. (SEP) the South-Eastern Pelagos sub-area, including transects from groups CTCV, PATU, N_TUCV, S_TUCV and CAPA. (AD) the Adriatic sub-area including transects from groups N_AP and S_AP.

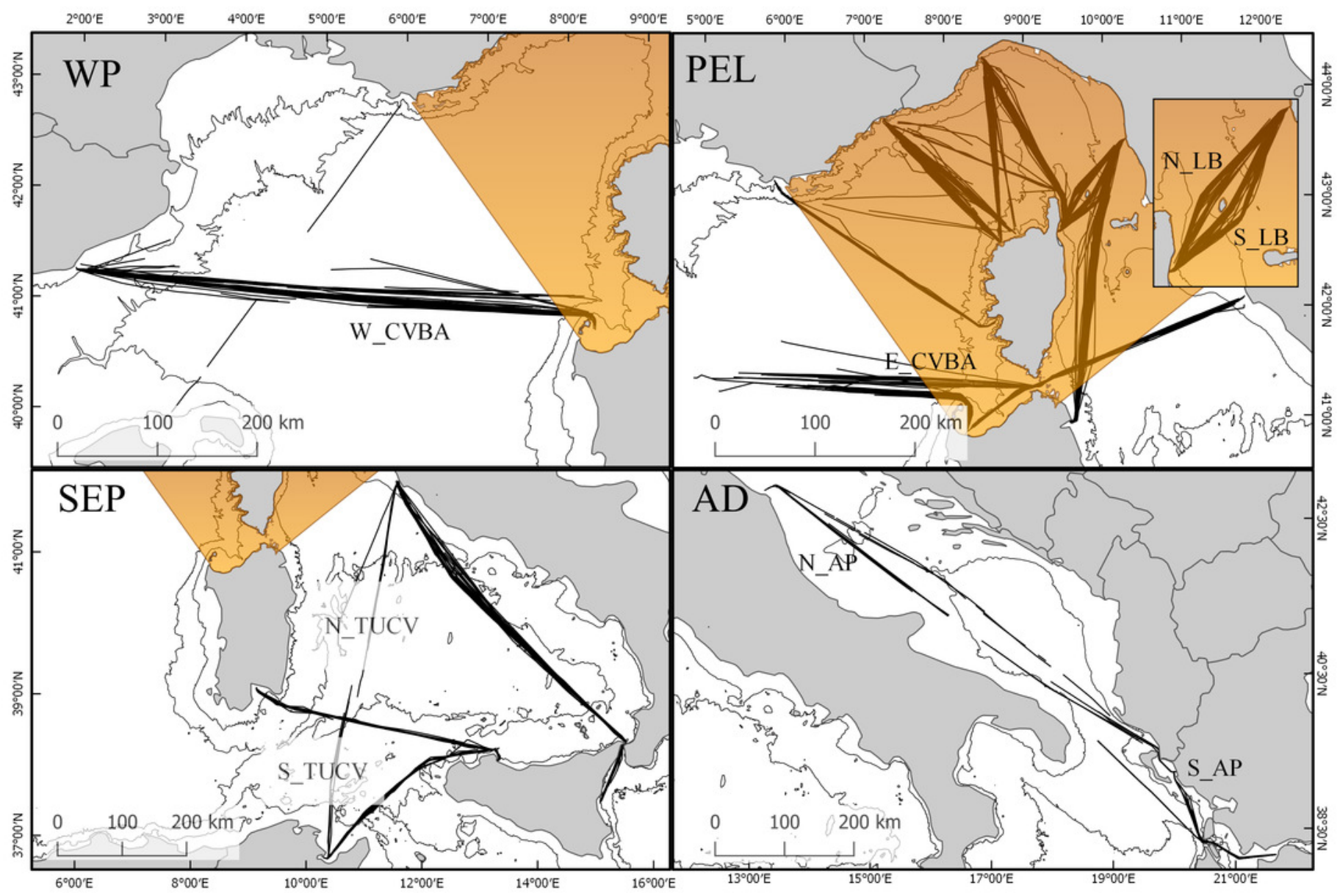


Figure 3

Frequency distribution of fin whale group sizes among sub-areas and per year

(A) Frequency distribution of fin whales group sizes among sub-areas. (B) Frequency distribution of group sizes among years in the WP sub-area. (C) Frequency distribution of group sizes among years in the PEL sub-area. (D) Frequency distribution of group sizes among years in the SEP sub-area.
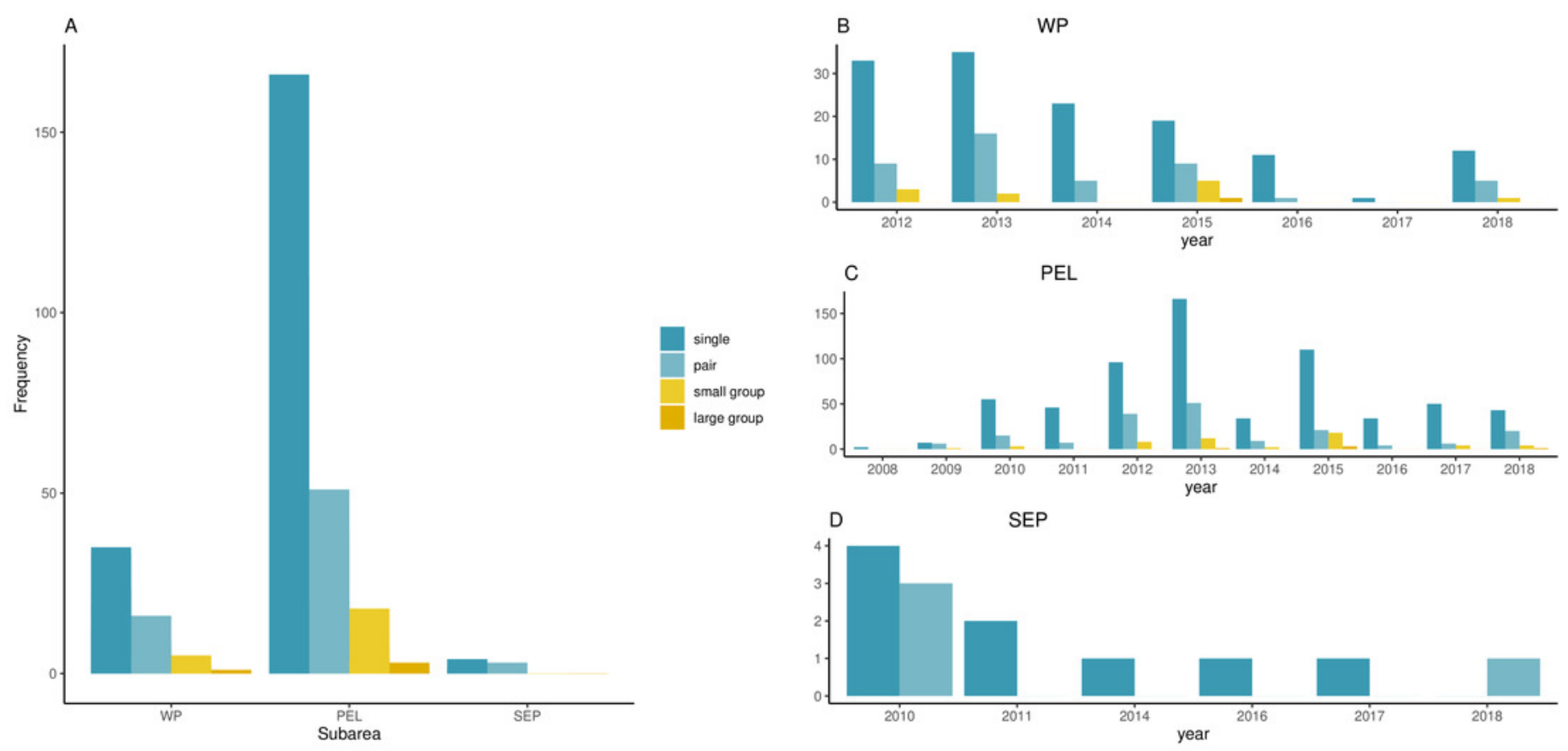
Figure 4

Density of fin whales in the study area and in the considered sub-areas

(A) Mean density of fin whales per year in the Western Mediterranean basin (B) Mean density of fin whales per year in the Western Pelagos (WP), Pelagos Sanctuary (PEL) and South Eastern PEelagos (SEP) sub-areas. Error bars represent 95\% Confidence Intervals
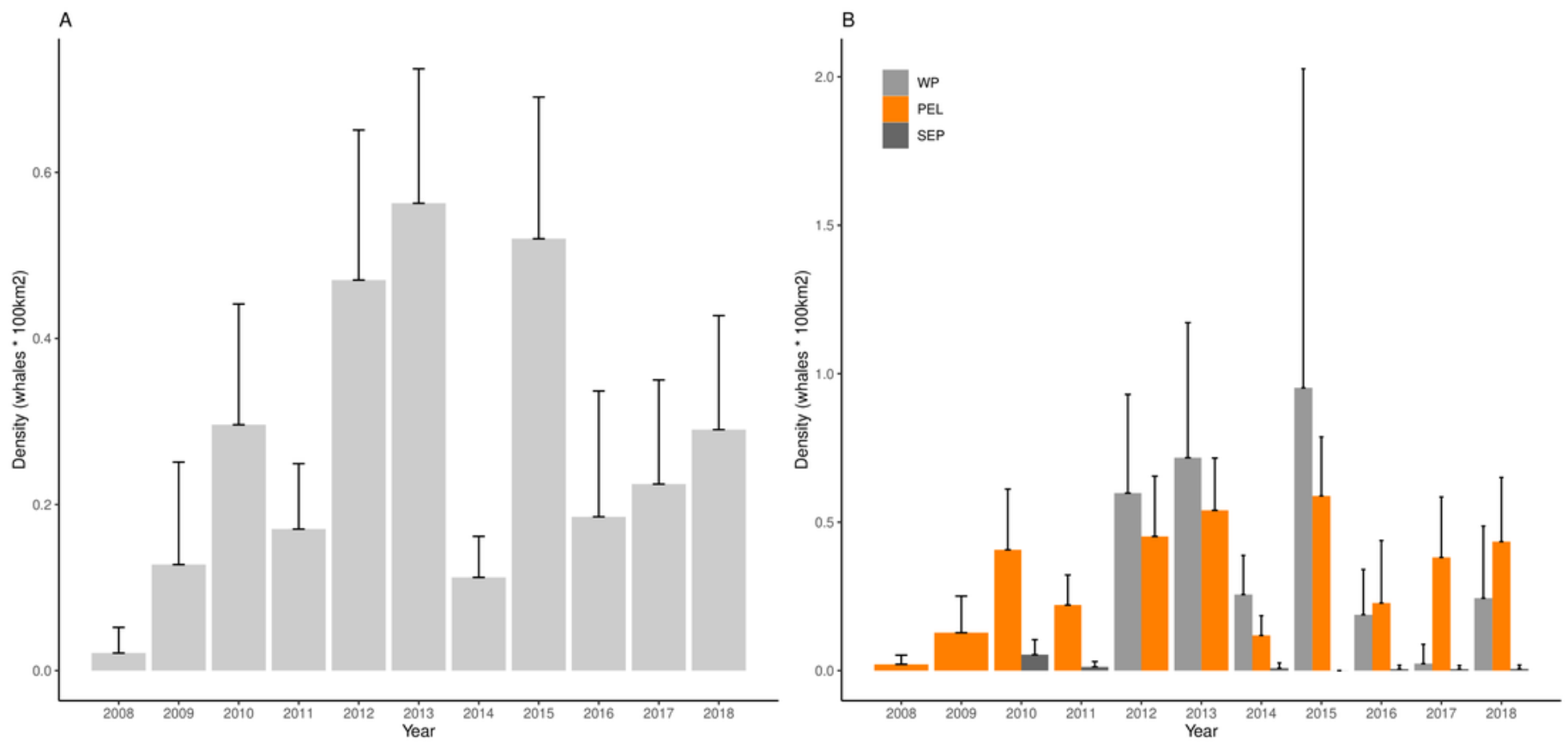


\section{Figure 5}

GAM plots showing fin whale density as a function of the year

Generalized additive model (GAM) predicted smooth splines of the fin whale density as a function of the year. Tick marks above the $x$-axis indicate the distribution of observations. Shaded area represents the $95 \%$ confidence interval of the smoothspline function. This plot can be used to understand trends of speciespresence in the Western Mediterranean Basin (A) as well as for the three sub-areas : Western Pelagos (B), Pelagos Sanctuary (C) and SouthEastern Pelagos (SEP). 
A

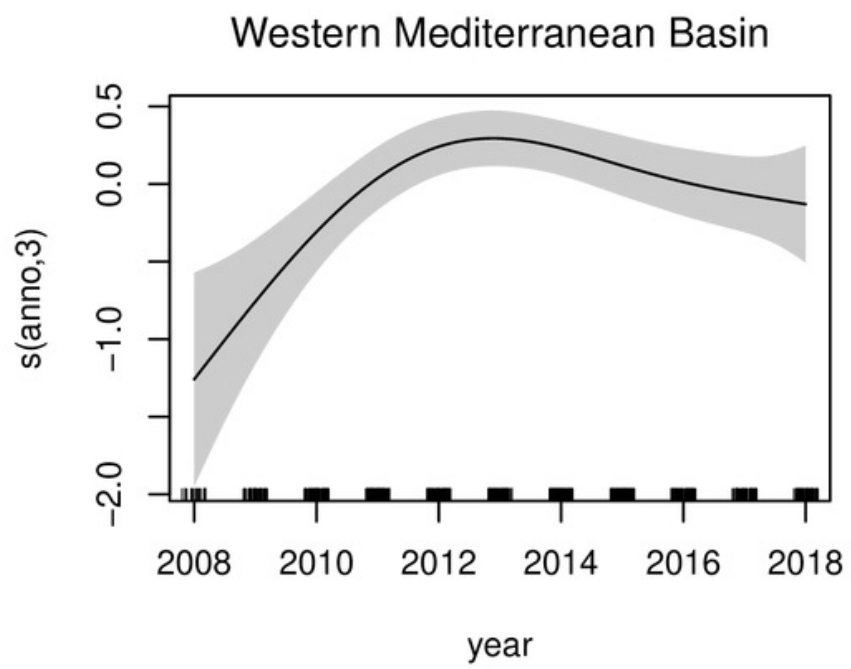

C

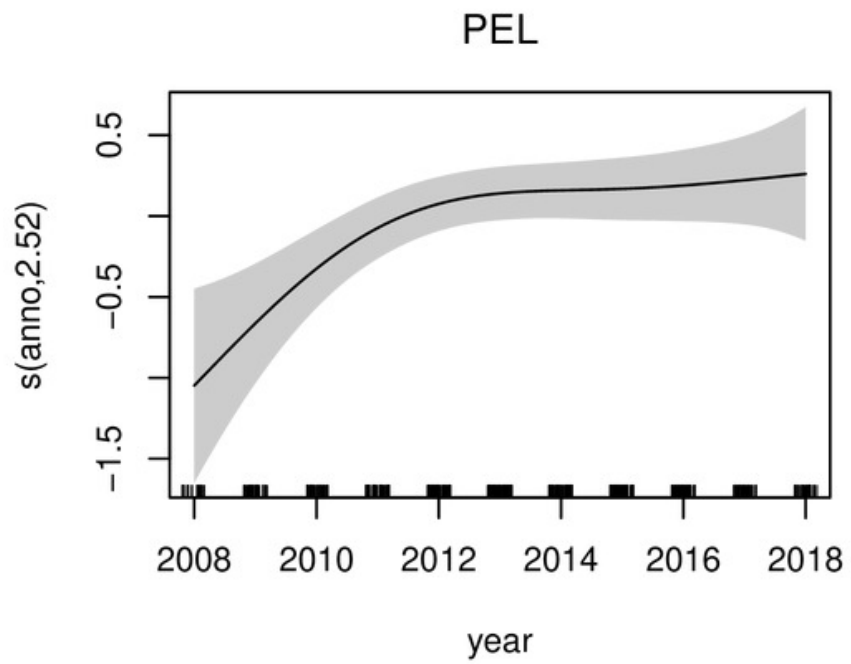

B

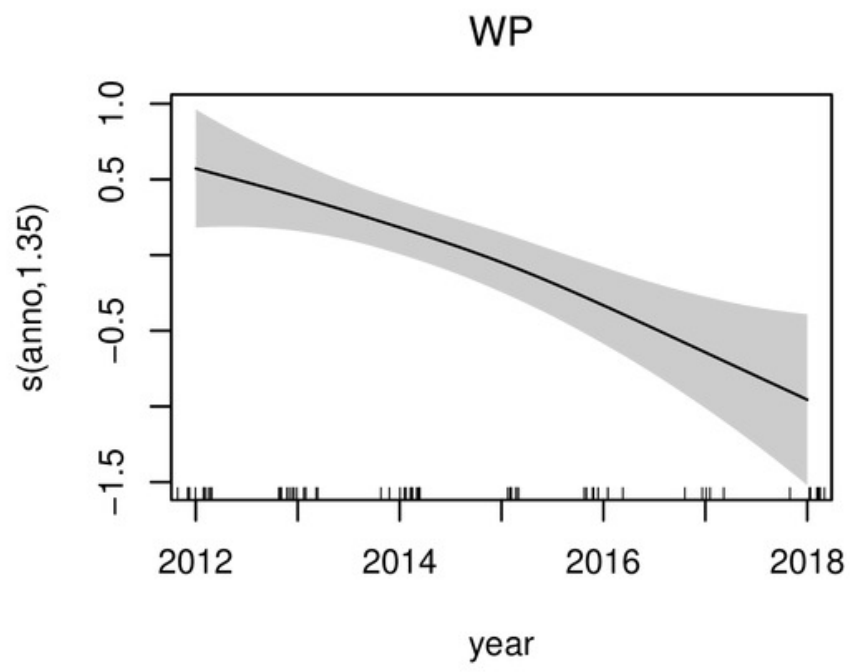

D

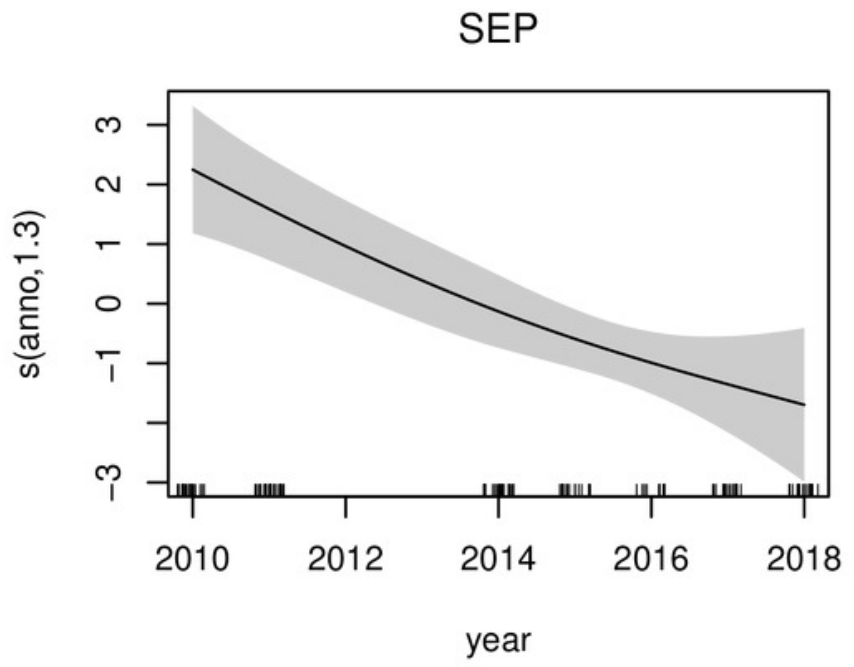




\section{Table $\mathbf{1}$ (on next page)}

Summary of routes and transect groups.

Summary of routes (see Figure 1 for reference), transect groups, sampled years, total number of transects monitored, number of transect discarded as not reaching the threshold value, maximum length of transects in the transect group and total $\mathrm{km}$ sampled along the route 
1

\begin{tabular}{|c|c|c|c|c|}
\hline Route & $\begin{array}{l}\text { Transect } \\
\text { group }\end{array}$ & Years & $\begin{array}{l}\mathrm{N}^{\circ} \text { transects } \\
\text { [discarded] }\end{array}$ & $\begin{array}{l}\text { Maximum - Total } \\
\text { Length (km) }\end{array}$ \\
\hline 1 Toulon - Alcudia & TAL & 2018 & 1 & $287.2-287.2$ \\
\hline 2 Toulon - Ajaccio & TAJ & $2011 ; 2014-2018$ & 34 & $265.26-7,664.89$ \\
\hline 3 Toulon - Ile rousse & $\mathrm{TI}$ & 2018 & 2 & $159.9-294.3$ \\
\hline 4 Toulon - Bastia & TB & 2018 & 1 & $195.8-195.8$ \\
\hline 5 Nice - Calvi/Ile Rousse ${ }^{1}$ & $\mathrm{NC}$ & $2009-2018$ & $193[8]$ & $165.71-26,409.85$ \\
\hline 6 Nice - Bastia & NB & $2017-2018$ & 7 & $217.33-1,286.85$ \\
\hline 7 Savona- Calvi/IleRousse & $\mathrm{SC}$ & $2013-2015 ; 2018$ & 52 & $178.01-7,954.03$ \\
\hline 8 Savona - Bastia & SB & $2008-2018$ & $260[27]$ & $189.32-38,127.85$ \\
\hline \multirow{2}{*}{9 Livorno - Bastia } & N_LB & $2008 ; 2010-2016$ & 73 & $115.03-7,874.55$ \\
\hline & S LB & $2008-2018$ & $141[1]$ & $119.32-14,531.67$ \\
\hline 10 Livorno - Golfo Aranci & LGA & $2012-2018$ & $110[1]$ & $298.49-26,051.97$ \\
\hline \multirow{2}{*}{11 Civitavecchia-Barcelona } & W_CVBA & \multirow{2}{*}{$2012-2018$} & $61[1]$ & $529.29-26,793.5$ \\
\hline & E_CVBA & & $62[2]$ & $537.17-24,698.46$ \\
\hline 12 Catania-Civitavecchia & CTCV & $2010-2011$ & 43 & $631.82-17,324.55$ \\
\hline 13 Palermo-Tunis & PATU & 2014-2018 & 27 & $349.26-6,423.87$ \\
\hline \multirow{2}{*}{14 Tunis-Civitavecchia } & N_TUCV & \multirow{2}{*}{ 2014-2015 } & 5 & $342.42-1,337.61$ \\
\hline & S_TUCV & & 4 & $275.92-1001.96$ \\
\hline 15 Cagliari - Palermo & CAPA & 2014-2018 & $52[1]$ & $396.59-13,577.55$ \\
\hline \multirow{2}{*}{16 Ancona - Patras } & N_AP & \multirow{2}{*}{$2015-2017$} & $11[1]$ & $439.83-2,785.84$ \\
\hline & S_AP & & $9[1]$ & $410.01-2,635.21$ \\
\hline
\end{tabular}

\footnotetext{
${ }^{1}$ Give the proximity of the two ports of Calvi and Ile-Rousse, trips directed to either of the two ports were considered as belonging to the same transect group
} 


\section{Table 2 (on next page)}

Results from Spearman's Correlation test

Results from Spearman's correlation test among transects of the same group performed the same day(or consecutive days) or the same week. 


\begin{tabular}{|l|l|l|l|}
\hline & \multicolumn{3}{|c|}{ DAY } \\
\hline & df & \multicolumn{1}{|c|}{$\rho$} & p-value \\
\hline NC & 77 & 0.59 & $7.816 \mathrm{e}-09$ \\
\hline SC & 23 & 0.69 & 0.0001413 \\
\hline SB & 108 & 0.57 & $6.626 \mathrm{e}-11$ \\
\hline LGA & 48 & 0.18 & 0.1991 \\
\hline CTCV & 19 & -0.15 & 0.5 \\
\hline \multicolumn{5}{|l|}{ WEEK } \\
\hline TAJ & 8 & -0.45 & 0.1906 \\
\hline NC & 66 & 0.35 & 0.003043 \\
\hline SC & 17 & 0.49 & 0.03218 \\
\hline SB & 93 & 0.35 & 0.0004112 \\
\hline N_LB & 23 & 0.45 & 0.02234 \\
\hline S_LB & 29 & -0.05 & 0.798 \\
\hline LGA & 25 & -0.14 & 0.4836 \\
\hline W_CVBA & 18 & 0.43 & 0.005881 \\
\hline E_CVBA & 18 & 0.18 & 0.4498 \\
\hline CTCV & 33 & -0.16 & 0.3522 \\
\hline CAPA & 29 & -0.06 & 0.74 \\
\hline & & & \\
\hline
\end{tabular}

1 


\section{Table 3(on next page)}

Yealy fin whale Desnities for the Western Mediterranean Basin and relative sub-areas

Yearly mean Density (D - whales * $100 \mathrm{~km}^{2}$ ) and $95 \%$ Confidence Interval, for the (a) entire study area and for the (b) different considered sub-areas 
1

\begin{tabular}{ll|c|l}
2 & Year & $\mathrm{D}\left(\right.$ whales $\left.* 100 \mathrm{~km}^{2}\right)$ & \multicolumn{1}{|c}{$95 \% \mathrm{CI}$} \\
\cline { 2 - 4 } 3 & 2008 & 0.02 & $-0.01-0.05$ \\
& 2009 & 0.13 & $0.00-0.25$ \\
4 & 2010 & 0.30 & $0.15-0.44$ \\
& 2011 & 0.17 & $0.09-0.25$ \\
5 & 2012 & 0.47 & $0.29-0.65$ \\
6 & 2013 & 0.56 & $0.40-072$ \\
6 & 2014 & 0.11 & $0.06-0.16$ \\
7 & 2015 & 0.52 & $0.35-0.69$ \\
8 & 2016 & 0.18 & $0.03-0.34$ \\
8 & 2017 & 0.22 & $0.10-0.35$ \\
9 & 2018 & 0.29 & $0.15-0.43$
\end{tabular}

a)

b)

11

\begin{tabular}{c|ccc} 
Year & & $\mathrm{D}(95 \% \mathrm{CI})$ & $\mathrm{SEP}$ \\
\hline & $\mathrm{WP}$ & $\mathrm{PEL}$ & $n a$ \\
2008 & $n a$ & $0.02(-0.01-0.05)$ & $n a$ \\
2009 & $n a$ & $0.13(0-0.25)$ & $0.05(0-0.10)$ \\
2010 & $n a$ & $0.22(0.12-0.32)$ & $0.01(-0.01-0.03)$ \\
2011 & $n a$ & $0.46(0.25-0.65)$ & $n a$ \\
2012 & $0.60(0.26-0.93)$ & $0.54(0.36-0.71)$ & $n a$ \\
2013 & $0.72(0.26-1.17)$ & $0.12(0.05-0.18)$ & $0.01(-0.010 .02)$ \\
2014 & $0.25(0.12-0.39)$ & $0.59(0.39-0.79)$ & 0 \\
2015 & $0.96(-0.12-2.03)$ & $0.23(0.02-0.44)$ & $0.01(-0.01-0.02)$ \\
2016 & $0.23(0.02-0.44)$ & $0.38(0.18-0.58)$ & $0.01(-0.01-0.02)$ \\
2017 & $0.02(-0.04-0.09)$ & $0.43(0.22-0.65)$ & $0.01(-0.01-0.02)$ \\
2018 & $0.24(0-0.49)$ & &
\end{tabular}

12

13

14 


\section{Table 4(on next page)}

Dunn's test results for the Western Mediterranean basin.

P-values of the Dunn's test are reported. Bold cells highlight significative differences among years ( $\alpha$ is set to $0.05, H_{0}$ is rejected if $P$-value is $>=\alpha / 2$ ). Along the diagonal, the number of differences from other years are summarized. 
1

\begin{tabular}{|c|c|c|c|c|c|c|c|c|c|c|c|}
\hline & 2008 & 2009 & 2010 & 2011 & 2012 & 2013 & 2014 & 2015 & 2016 & 2017 & 2018 \\
\hline 2008 & 6 & 0.2298 & 0.0033 & 0.0519 & 0.0001 & 0.0000 & 0.0528 & 0.0000 & 0.0439 & 0.0220 & 0.0028 \\
\hline 2009 & & 5 & 0.0080 & 0.1527 & 0.0001 & 0.0000 & 0.1565 & 0.0000 & 0.1270 & 0.0635 & 0.0067 \\
\hline 2010 & & & 3 & 0.0375 & 0.0491 & 0.0023 & 0.0295 & 0.0376 & 0.0754 & 0.1781 & 0.4783 \\
\hline 2011 & & & & 3 & 0.0001 & 0.0000 & 0.4791 & 0.0001 & 0.4138 & 0.2381 & 0.0313 \\
\hline 2012 & & & & & 6 & 0.1122 & 0.0001 & 0.4546 & 0.0008 & 0.0053 & 0.0530 \\
\hline 2013 & & & & & & 8 & 0.0000 & 0.1325 & 0.0000 & 0.0001 & 0.0025 \\
\hline 2014 & & & & & & & 4 & 0.0000 & 0.3928 & 0.2178 & 0.0242 \\
\hline 2015 & & & & & & & & 6 & 0.0005 & 0.0037 & 0.0406 \\
\hline 2016 & & & & & & & & & 3 & 0.3206 & 0.0661 \\
\hline 2017 & & & & & & & & & & 4 & 0.1626 \\
\hline 018 & & & & & & & & & & & 4 \\
\hline
\end{tabular}

2 


\section{Table 5 (on next page)}

Dunn's test results for the PEL and WP sub-areas.

P-values of the Dunn's test for the (a) PEL sub-area and for the (b) WP sub-area are reported. Bold cells highlight significative differences among years ( $\alpha$ is set to $0.05, \mathrm{H}_{0}$ is rejected if $\mathrm{P}$ value is $>=\alpha / 2$ ). Along the diagonal, the number of differences from other years are summarized. 
1 a)

\begin{tabular}{|c|c|c|c|c|c|c|c|c|c|c|c|}
\hline & 2008 & 2009 & 2010 & 2011 & 2012 & 2013 & 2014 & 2015 & 2016 & 2017 & 2018 \\
\hline 2008 & 3 & 1 & 0.0293 & 1 & 0.0285 & 0.0009 & 1 & 0.0003 & 1 & 0.0397 & 0.0079 \\
\hline 2009 & & 3 & 0.0563 & 1 & 0.0464 & 0.0005 & 1 & 0.0002 & 1 & 0.0870 & 0.0125 \\
\hline 2010 & & & 0 & 1 & 1 & 1 & 0.2457 & 1 & 1 & 1 & 1 \\
\hline 2011 & & & & 1 & 1 & 0.0527 & 1 & 0.0166 & 1 & 1 & 0.5170 \\
\hline 2012 & & & & & 0 & 1 & 0.2022 & 1 & 1 & 1 & 1 \\
\hline 2013 & & & & & & 3 & 0.0015 & 1 & 0.0446 & 1 & 1 \\
\hline 2014 & & & & & & & 3 & 0.0004 & 1 & 0.3650 & 0.0534 \\
\hline 2015 & & & & & & & & 5 & 0.0150 & 1 & 1 \\
\hline 2016 & & & & & & & & & 1 & 1.0000 & 0.3387 \\
\hline 2017 & & & & & & & & & & 0 & 1 \\
\hline 2018 & & & & & & & & & & & 2 \\
\hline
\end{tabular}

3

4 b)

\begin{tabular}{r|rrrrrrr}
\multicolumn{1}{l}{2012} & 2013 & 2014 & 2015 & 2016 & 2017 & 2018 \\
\hline 2012 & 1 & 1 & 1 & 1 & 0.7304 & $\mathbf{0 . 0 2 0 2}$ & 0.9217 \\
2013 & & 1 & 0.8325 & 1 & 0.4359 & $\mathbf{0 . 0 0 9 2}$ & 0.5509 \\
2014 & & & 0 & 1 & 1 & 0.5133 & 1 \\
2015 & & & & 0 & 0.7285 & 0.0269 & 0.9107 \\
2016 & & & & & 0 & 1 & 1 \\
2017 & & & & & & 2 & 1 \\
2018 & & & & & & & 0
\end{tabular}

5 


\section{Table 6(on next page)}

\section{Results of GAMs}

Results of the Generalized Additive Models area reported. (a) GAMs for the Western Mediterranean Basin and for the three considered sub-areas. (b) GAM for the PEL sub-area, adding the transect group as an explanatory variable 
1 a)

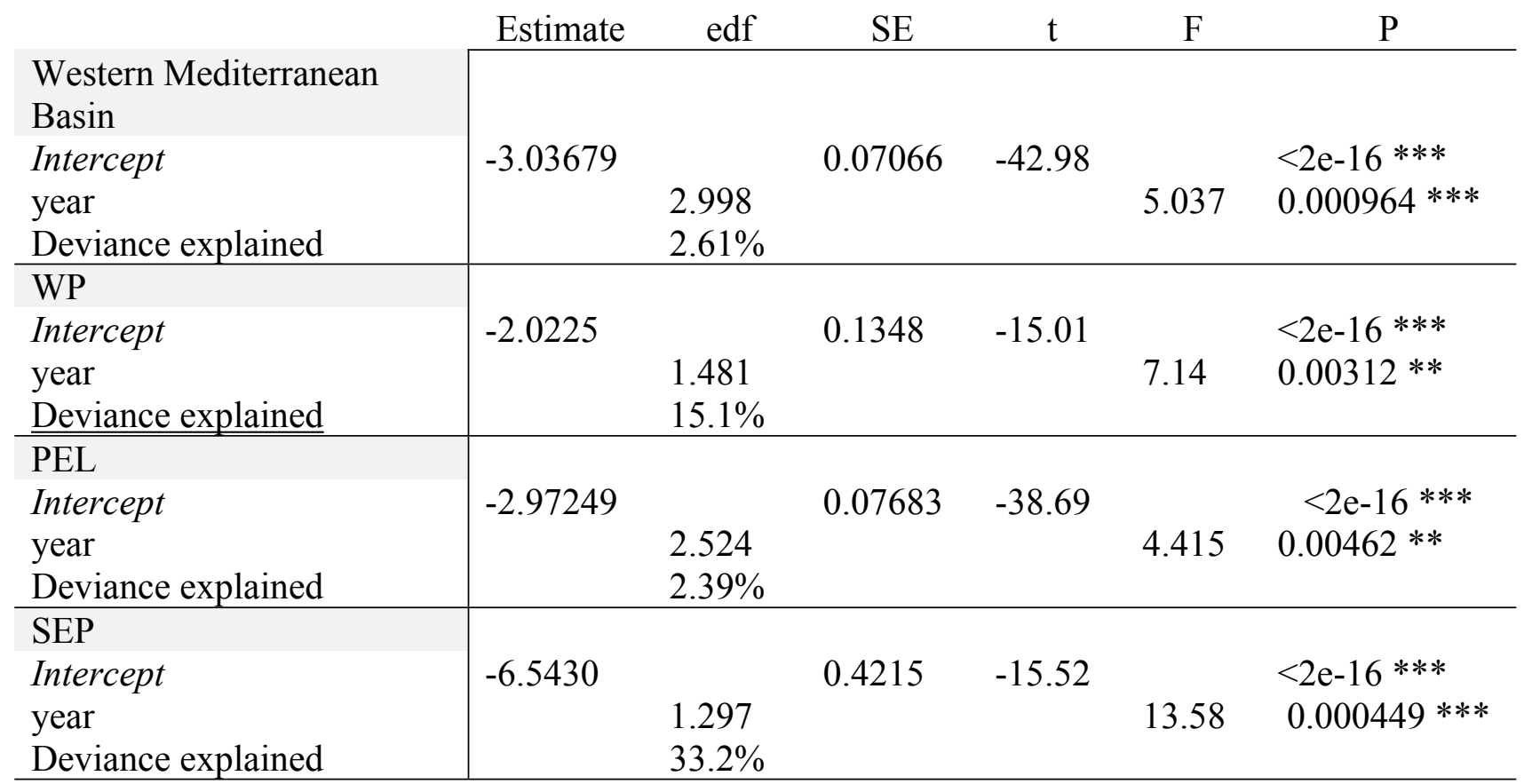

2 b)

PEL

Intercept

TI

TB

$\mathrm{NC}$

NB

$\mathrm{SC}$

SB

LB

LGA

E_CVBA

Smooth term

year

Deviance explained

\begin{tabular}{|c|c|c|c|c|c|}
\hline Estimate & edf & SE & $\mathrm{t}$ & $\mathrm{F}$ & $\mathrm{P}$ \\
\hline-2.3663 & & 0.2034 & -11.585 & & $<2 \mathrm{e}-16 * * *$ \\
\hline-57.0810 & & 68080.9145 & -0.001 & & 0.999 \\
\hline-2.9701 & & 1.196 & -1.352 & & 0.177 \\
\hline 0.1646 & & 0.2274 & 0.724 & & 0.469 \\
\hline-0.9905 & & 0.6048 & -1.638 & & 0.102 \\
\hline 0.4763 & & 0.2938 & 1.621 & & 0.105 \\
\hline-1.1578 & & 0.2457 & -4.712 & & $3.06 \mathrm{e}-06 * * *$ \\
\hline-3.9503 & & 0.4001 & -9.873 & & $<2 \mathrm{e}-16 * * *$ \\
\hline-3.8395 & & 0.4444 & -8.639 & & $<2 \mathrm{e}-16 * * *$ \\
\hline 0.2890 & & 0.2706 & 1.068 & & 0.286 \\
\hline & $\begin{array}{l}2.964 \\
44.1 \%\end{array}$ & & & 2.3333 & 0.0453 \\
\hline
\end{tabular}

3 